\title{
Mucin exocytosis: a major target for Helicobacter pylori
}

\author{
I Micots, C Augeron, C L Laboisse, F Muzeau, F Mégraud
}

\begin{abstract}
Aims: To determine whether Helicobacter pylori impairs the secretory function of mucous cells.

Methods: The mucus secreting human cell line CL. 16E, maintained as confluent monolayers on nitrocellulose filters, was infected with $H$ pylori strain CIP 101260. After three hours of incubation with $H$ pylori the monolayers were washed and reincubated with fresh culture medium for various time periods $(24,48$, or 72 hours) before evaluating both the morphology and function of mucous cells. For morphological studies, epithelial monolayers were fixed in situ and processed for both standard histochemistry on paraffin wax sections, and electron microscopy. To measure mucins secreted from cultured cells, the cells were metabolically labelled with ${ }^{3} \mathbf{H}$-glucosamine. Undegraded mucins were quantitated as the radioactive glycoproteins blocked at the stacker gel interface after sodium dodecyl sulphatepolyacrylamide gel electrophoresis of the secretory glycoproteins.
\end{abstract}

Results: Control cultures of $\mathrm{Cl}$. $16 \mathrm{E}$ cells grew on filters as homogeneous monolayers of polarised mucous cells secreting a visco-elastic gel of mucins at the apical surface. In infected monolayers $H$ pylori was in close contact with the apical surface of mucous cells. Cell counts and histological evaluation of the monolayers did not reveal any significant deleterious effect of $H$ pylori on the mucous cells. $H$ pylori induced only a modest inhibition of baseline mucus secretion from $\mathrm{Cl}$. 16E cells, this inhibition being significant only at 24 hours. In contrast, the mucus secretory response to two agents that raise intracellular cAMP and calcium-forskolin and ionophore A23187-was strongly inhibited. The inhibitory effect of $H$ pylori on the exocytotic response was not paralleled by an inhibition of glycoprotein synthesis.

Conclusion: Considering the fact that the exocytotic response to a variety of secretagogues constitutes the primary line of defence of the gastric mucosa in an emergency, it is suggested that $H$ pylori exerts its deleterious effects by weakening this important physiological defence.

(F Clin Pathol 1993;46:241-245)

Helicobacter pylori is now recognised as the main cause of antral gastritis and is implicated as an aetiological agent in duodenal ulcer disease. ${ }^{1}$ However, despite fairly intensive studies, the pathogenic mechanisms of $H$ pylori, either direct or indirect, are still poorly understood. Several morphological studies have contributed important information with regard to the interaction of $H$ pylori with gastric epithelial cells ${ }^{2-5}$ In particular, the finding of a close association of $H$ pylori with the apical surface of mucous cells in the gastric pits ${ }^{4}$ strongly suggests that $H$ pylori can interfere with the function of these specialised cells. In view of the fact that mucus glycoproteins provide the first line of defence for gastric mucosa, the hypothesis that $H$ pylori exerts its deleterious effects by impairing the secretory function of mucous cells should be examined.

The ideal cellular model for testing this hypothesis would be a monolayer culture of mucous cells that have retained in vitro the regulatory mechanisms operative in the same cells in vivo. However, it is still impossible to maintain normal human gastric mucous cells in culture.

A human epithelial cell line, $\mathrm{Cl} .16 \mathrm{E}^{6}$, which is differentiated into monolayers of polarised mucous cells is now available. Several studies have shown that $\mathrm{Cl}$. 16E cells have retained in vitro the regulatory mechanisms of mucus secretion of normal mucous cells in vivo. ${ }^{7-9}$

\section{Methods}

$H$ pylori strain CIP 101260 isolated from an antral biopsy specimen in a patient with chronic antral gastritis was used in this study. ${ }^{10}$ The strain was maintained frozen at $-70^{\circ} \mathrm{C}$ before testing. Culture was performed on Wilkins Chalgren agar (Oxoid, Basingstoke, England) supplemented with $10 \%$ human blood and antibiotics (vancomycin, cefsulodin, and actidione), and incubated for 24 hours in a microaerobic atmosphere.

The $\mathrm{Cl}$. $16 \mathrm{E}$ cell line is a stable, differentiated derivative of the human colonic cancer cell line HT29. ${ }^{11} \mathrm{Cl}$. $16 \mathrm{E}$ cells are morphologically ${ }^{6}$ and functionally ${ }^{7}$ differentiated into typical mucous cells. $\mathrm{Cl}$. 16E cells were routinely cultured in $25 \mathrm{~cm}^{2}$ plastic flasks (Falcon, Paris, France) in Dulbecco's modified medium (DMEM) (Gibco, Paris, France) supplemented with $10 \%$ heat inactivated fetal calf serum (FCS) (Gibco). All cultures were free of mycoplasma contamination, as tested periodically by the method of Chen. ${ }^{12}$ Culture on filters was performed as described previously. $^{79}$ Experiments began on day 8 after seeding, when the cells were covered with a
Correspondence to: Dr F Mégraud

Accepted for publication 12 August 1992 
visible mucus gel.

The cell monolayers were washed and $100 \mu \mathrm{l}$ of a suspension of $H$ pylori $(O D=0.8$ at $600 \mathrm{~nm}$ ) prepared in sterile brucella broth was added to each dish containing $2.5 \mathrm{ml}$ of culture medium. Control cultures were incubated without $H$ pylori. Incubation was at $37^{\circ} \mathrm{C}$ in the presence of $10 \% \mathrm{CO}_{2}\left(\mathrm{CO}_{2}\right.$ gas generating kit, Oxoid). After three hours of incubation, the non-adherent bacteria were removed by washing the cell monolayers with three changes of phosphate buffered saline. The monolayers were reincubated in standard medium (DMEM, 10\% FCS). In other experiments $\mathrm{D}-\left(6-{ }^{3} \mathrm{H}\right)$-glucosamine was added for 24-72 hours to study mucus secretion.

At indicated time periods, filters were fixed in Bouin's fluid, cut into strips, and embedded in paraffin wax. Cross sections of filters were stained with haematoxylin and eosin, and with alcian blue $(\mathrm{pH}=2 \cdot 5)$ for mucin staining. Filters were also processed for transmission electron microscopy, as previously described. ${ }^{13}$

A monodispersed cell suspension of the filter grown cells was obtained using a two-step dissociation method ${ }^{6}$ and cells were counted in a haemacytometer. Cell viability was assessed by trypan blue exclusion.

Metabolic labelling of filter grown cells (control cultures and $H$ pylori-infected cultures) was performed to measure mucin secretion using the precursor $\mathrm{D}-\left(6-{ }^{3} \mathrm{H}\right)$-glucosamine hydrochloride $(10 \mu \mathrm{Ci} /$ filter, specific activity $20-40 \mathrm{Ci} / \mathrm{mmol}$ ) (Amersham) in DMEM, 10\% FCS. At indicated time periods, the incubation medium was removed using a pipet and the monolayers were rinsed with the spent medium to remove adherent mucin Then the incubation medium was dialysed for 36-48 hours against several changes of deionised water at $4^{\circ} \mathrm{C}$ and lyophilised. The secretory glycoproteins were then separated by sodium dodecyl sulphate-polyacrylamide gel electrophoresis on $3 \%$ gels. After electrophoresis, each lane of the stacking gel containing the ${ }^{3} \mathrm{H}$-mucin glycoproteins was cut out, then put into a borosilicate phial and incubated overnight at $40^{\circ} \mathrm{C}$ in the presence of $500 \mu \mathrm{l}$ of Soluene 350 (Packard). The phials were allowed to cool, and $10 \mathrm{ml}$ of a solution of Pico-fluor 40 (Packard) was added to each phial. The radioactivity was counted in an LKB scintillation counter. This assay was referred to as the "electrophoretic assay".

The exocytotic response to ionophore A23187 and forskolin was measured using the release of ${ }^{3} \mathrm{H}$-mucin as an index of triggered exocytosis. First intracellular mucin granules were labelled by incubating cell monolayers with ${ }^{3} \mathrm{H}$-glucosamine as indicated above. At the end of the incubation period, the filters were washed three times and transferred into the wells of a multiwell culture plate containing Ham-DMEM $(600 \mu 1 /$ well) with $0.01 \%$ bovine serum albumin (w/v), $4 \cdot 10^{-5} \mathrm{M}$ ionophore A23187 (Sigma Chemicals, St. Louis, Missouri, USA), and $10^{-4} \mathrm{M}$ forskolin (Calbiochem Corporation, La Jolla, California, USA). After 45 minutes of incubation, the medium was removed and the monolayers were rinsed with the spent medium to remove adherent mucin. Then the secreted mucins were measured using the "electrophoretic assay".

Prior to the intracellular incorporation studies, the cell monolayers were incubated with or without (control) $H$ pylori for three hours then washed and reincubated for 24 hours in DMEM with $10 \%$ FCS, according to the previously described protocol. The monolayers were incubated for three hours in $600 \mu \mathrm{l}$ of serum-free medium containing $10 \mu \mathrm{Ci} / \mathrm{ml}$ of $\mathrm{D}$ - $\left(6-{ }^{3} \mathrm{H}\right)$-glucosamine hydrochloride. At the end of the incubation period, the filters were washed three times in $0.9 \% \mathrm{NaCl}$ without glucosamine, and the cells were scraped from filters with a rubber policeman in $2.5 \mathrm{ml}$ of a $0.9 \% \mathrm{NaCl}$ solution. Then the cells were sonicated for 30 seconds.

Incorporation of $\mathrm{D}-\left(6-{ }^{3} \mathrm{H}\right)$-glucosamine into acid precipitable glycoproteins of the cell homogenates was measured by adding cold trichloroacetic acid (TCA) and phosphotungstic acid (PTA) at a final concentration of $10 \%$ and $1 \%$, respectively, to an aliquot of the homogenate. After an overnight incubation at $4^{\circ} \mathrm{C}$ the precipitate was collected by centrifugation, washed with an additional $1 \mathrm{ml}$ of TCAPTA, then with $1 \mathrm{ml}$ of chloroform-methanol $(1: 1, \mathrm{vol} / \mathrm{vol})$ and dried. The pellet was moistened by adding $50 \mu \mathrm{l}$ of water and then dissolved in Soluene 350 (Packard). Radioactivity was determined after addition of $5 \mathrm{ml}$ of Pico-fluor 40 in a liquid scintillation counter.

Results are expressed as the mean (SEM). Comparison between cells incubated with mediators and control cells was assessed with a Student's $t$ test.

\section{Results}

Confluent cultures of $\mathrm{Cl}$. $16 \mathrm{E}$ cells on nitrocellulose filters formed homogeneous monolayers of polarised mucous cells. The cell number remained constant throughout the incubation period in control cultures.

Electron microscopic examination of infected monolayers disclosed numerous organisms which were in close contact with the apical membrane of mucous cells (fig 1) as well as in clusters in the mucus layer. Their location was restricted to the apical membrane with apparently no preference for the region close to intercellular junctions. They were detected as early as 24 hours after inoculation and were present on each section studied after 48 hours. Finally, $H$ pylori did not induce major ultrastructural changes in mucous cells over a 48 hour period.

Histological evaluation of the monolayers on cross-sections did not disclose major modifications on infection with $H$ pylori. Cell monolayers examined 24 hours after inoculation with $H$ pylori did not differ from controls. Only minor morphological changes were observed after 48 hours of incubation. They consisted of a slight disorganisation of the monolayers without erosion. Cell counts confirmed the 
Figure 1 Transmission electron micrograph of

Cl. $16 E$ cells infected with

Helicobacter pylori for three days. Numerous organisms are present in close

association with the apical membrane of the mucous cells.

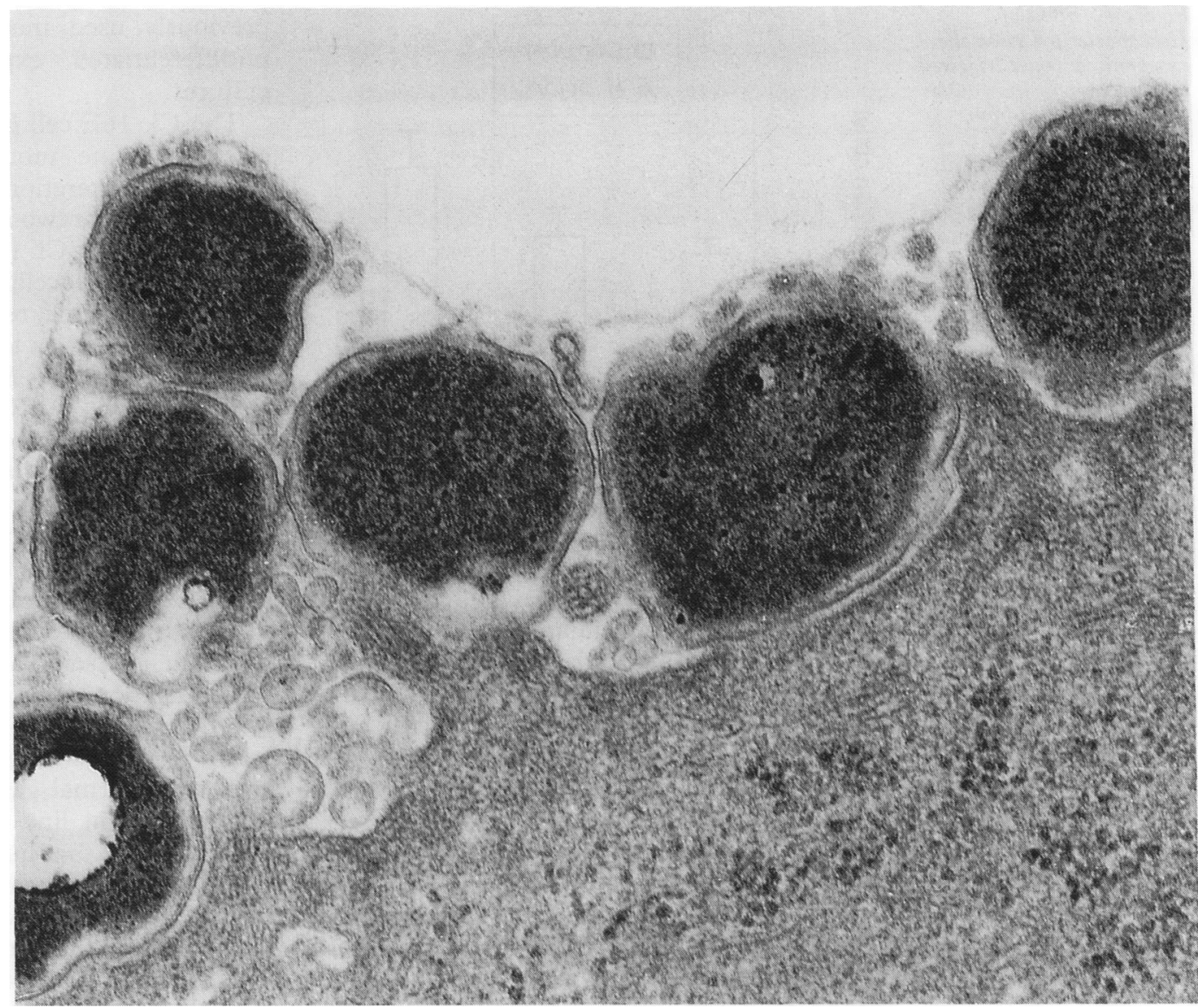

absence of deleterious effects of $H$ pylori on mucous cells (fig 2), since there was no significant variation in cell number between control and $H$ pylori-infected cells over a 72 hour incubation period.

As shown in fig 3, baseline secretion from control cultures was linear over a 72 hour period. The amount of radioactive mucus recovered from culture media of $H$ pyloriinfected cells was significantly lower than in control cultures for the first 24 hour incubation period. When incubation was prolonged to 48 or 72 hours, the concentration of mucus in $H$ pylori-infected cultures did not significantly differ from controls.

To obtain further insight into the effects of $H$ pylori on mucus secretion, we measured the mucin secretory rate after a 45 minute stimula-

Figure 2 Kinetic properties of filter grown Cl. $16 E$ cells with or without Helicobacter pylori. Cells were counted 24,48 , and 72 hours after infection. Each point represents the mean (SEM) of four experiments with three determinations per experiment. tion of $\mathrm{Cl}$. $16 \mathrm{E}$ cells with ionophore $23187 /$ forskolin. As shown in fig 4, a combination of these two agents triggered a strong exocytotic response from control cultures. In contrast, the secretory response triggered by the combination of ionophore 23187 /forskolin was inhibited by nearly $50 \%$ in infected cells at time points 24,48 , and 72 hours.

In view of our findings showing that the exocytosis of mucins was severely impaired in $H$ pylori-infected mucous cells, it was important to examine whether $H$ pylori was also able to inhibit intracellular glycoprotein synthesis.

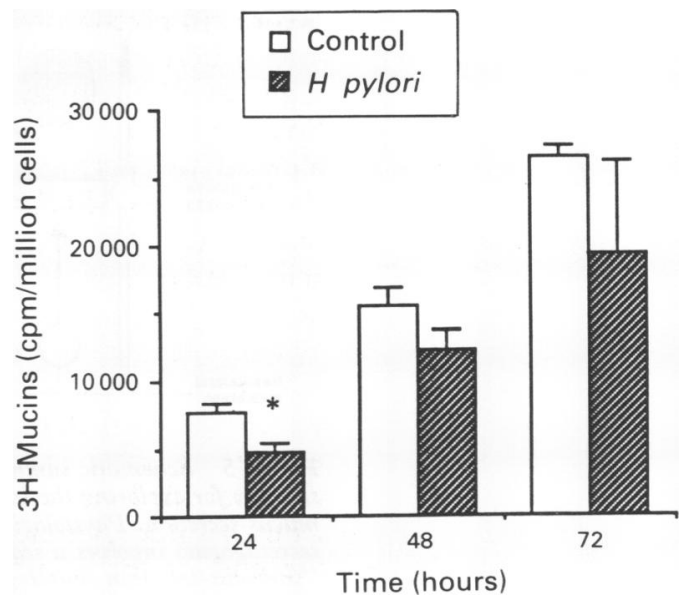

Figure 3 Effect of Helicobacter pylori on baseline secretion of mucins from $\mathrm{Cl}$. $16 \mathrm{E}$ cells. Infected monolayers and controls were metabolically labelled with

${ }^{3} \mathrm{H}$-glucosamine for 24,48 , or 72 hours. Extracellular mucins were measured as described in Methods. Each point represents the mean (SEM) of three experiments with three determinations per experiment. ${ }^{*} H$ pylori induced a significant decrease in baseline secretion at time point 24 hours $(p<0.03)$.

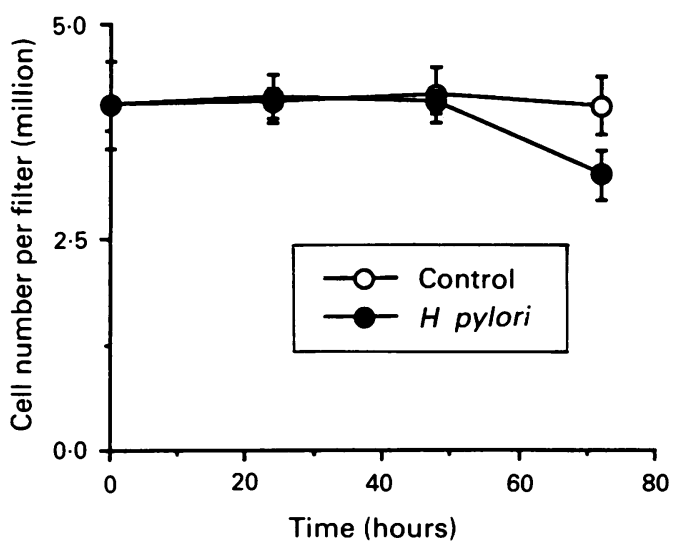


Figure 4 Effect of Helicobacter pylori on the exocytotic response triggered by ionophore A23187/forskolin from Cl. $16 E$ cells. Metabolically labelled cells were rinsed and then incubated for 45 minutes in Ham-DMEM containing secretagogues. Extracellular mucins were measured as described in "Methods". Each point represents the mean (SEM) of three experiments with three determinations per experiment. *Denotes significant difference from controls $(p<0.03)$.

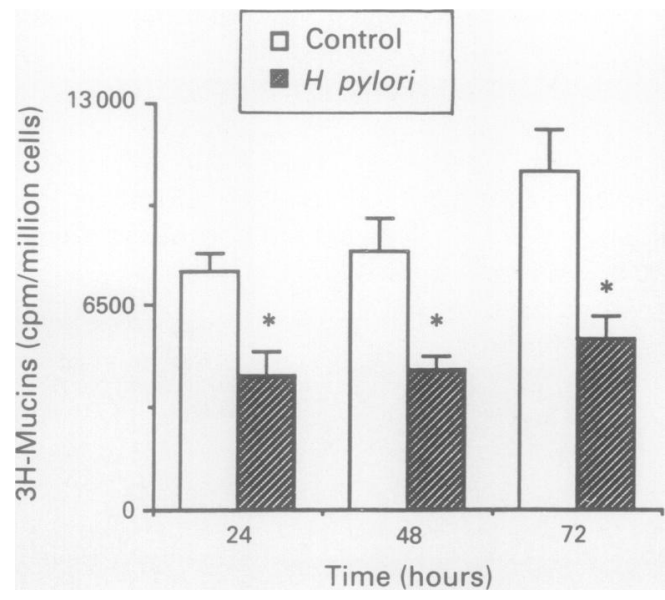

For this purpose, the incorporation of ${ }^{3} \mathrm{H}$-glucosamine into intracellular glycoproteins was measured according to the method of Lamont and Ventola. ${ }^{14}$ The glycoprotein biosynthesis in $H$ pylori-infected cells was not significantly different from control cultures 24 hours after inoculation.

\section{Discussion}

This study provides the first demonstration that $H$ pylori infection can directly impair the secretory function of mucous cells. Our evidence is based on a unique experimental approach using a homogeneous human mucous cell line (Cl. 16E). Cl. 16E cells can be maintained in vitro as fully polarised cell monolayers having the kinetic characteristics of an epithelium in steady state-that is, cell production and cell loss are balanced so that the cell population remains constant. These in vitro characteristics are close to the in vivo situation. This contrasts with most of the

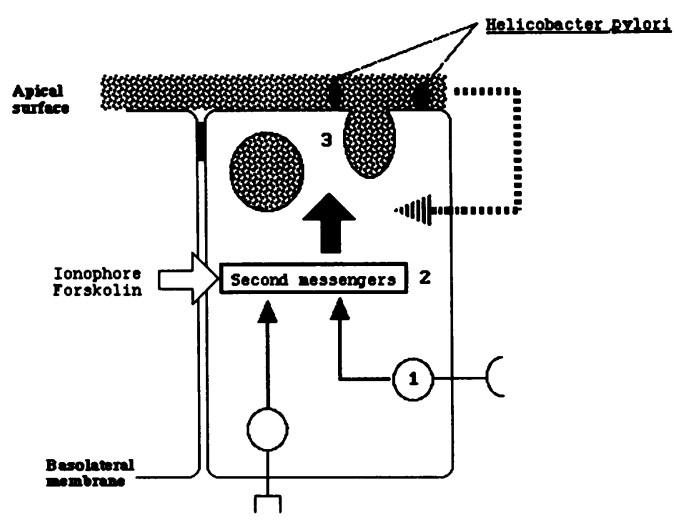

Figure 5 Schematic summary of the experimental strategy for exploring the interaction of $H$ pylori with mucus secretion. Physiologically the exocytotic response to secretagogues involves a sequence of events referred to as "stimulus-secretion coupling": external signals

(secretagogues) which bind to specific receptors acting via regulatory $G$ proteins (1) on intracellular messengers (2), such as $\mathrm{CAMP}$ or $\mathrm{Ca}^{++}$, which evoke movement of secretory granules to the luminal plasma membrane (3).

Pharmacological agents (ionophore A23187, forskolin) which act directly at intracellular messenger level to explore the final step in stimulus secretion coupling

phenomena-exocytosis. The dotted line indicates inhibitory action of $H$ pylori on the exocytotic mechanisms. previously used models which consisted of undifferentiated, exponentially growing cell cultures.

The $\mathrm{Cl} .16 \mathrm{E}$ cell line may be considered as an appropriate model system for studying functional alterations of $H$ pylori-infected mucous cells for two reasons: (i) several studies have shown that $\mathrm{Cl}$. 16E maintained as floating cultures on nitrocellulose filters have retained in vitro the same regulatory mechanisms of mucus secretion as those operating in vivo ${ }^{79}$; and (ii) $H$ pylori was found to adhere to the cell surface of $\mathrm{Cl}$. $16 \mathrm{E}$ cells in a way which mimicked the in vivo situation (this study). In particular, the location of $H$ pylori to the apical surface of mucous cells agrees with previous ultrastructural observations in vivo. ${ }^{3-5}$ Interestingly, $\mathrm{Cl}$. $16 \mathrm{E}$ cells, which are of colonic origin, resemble human gastric mucous cells in their immunocytochemical reactions: support for such a resemblance has come from the demonstration that polyclonal antibodies raised against $\mathrm{Cl}$. 16E secretory mucins were found to react strongly on immunocytochemistry with normal gastric epithelium. ${ }^{15}$ These findings are in line with other experimental work showing that human colonic cancer cells may express antigenic determinants which are normally restricted to gastric mucous cells in the human adult. ${ }^{16}$ In view of these findings it is conceivable that the adherence of the organism to $\mathrm{Cl}$. $16 \mathrm{E}$ cells is in relation to the naturally occurring situation.

Several important findings regarding both morphology and function of $H$ pylori-infected mucous cells are highlighted by this study: $H$ pylori did not induce major cellular morphological changes nor did it exert a major cytotoxic effect on $\mathrm{Cl}$. $16 \mathrm{E}$ cells over a 72 hour incubation period. This is consistent with the results of other ultrastructural studies which led to the conclusion that, apart from some distortion and depletion of microvilli, $H$ pylori do not cause pathological changes in mucosal epithelial cells, even when they are in membrane to membrane contact with each other. ${ }^{4}$

Given that the principal function of gastric mucous cells is to protect the mucosa by secreting a visco-elastic gel of mucus, it may be assumed that this secretory process is an important target for $H$ pylori. In the normal gastric mucosa the extracellular mucus blanket is contributed by (i) the baseline secretion of the contents of stored intracellular granules and (ii) the accelerated exocytosis of stored granules under acute stimulation. The acute stimulation is triggered by neuroendocrine agents as well as by mediators released by inflammatory cells. ${ }^{17}$ These various agents act on specific receptors at the cell surface. It is generally assumed that the acute stimulation is the major contributor to a protective layer of mucins in response to an "emergency" situation.

It was therefore important to explore these two mechanisms, first by measuring the baseline secretion of mucus from $H$ pylori-infected cells, and second by measuring the exocytotic response of these cells to known secretagogue agents. 
From our results, it is clear that $H$ pylori induced only a modest inhibition of baseline secretion from $\mathrm{Cl}$. $16 \mathrm{E}$ cells, this inhibition being significant only at time point 24 hours. In contrast, $H$ pylori had a major inhibitory effect on the stimulated exocytosis of mucins at all time points tested.

Our approach was based on two agents which are known to trigger rapid exocytosis of mucus granules by stimulating two important intracellular signalling pathways of secretory cells-cAMP and $\mathrm{Ca}^{++}$. Knowing the intracellular sites of action of these agents, our finding of an inhibitory effect of $\mathrm{H}$ pylori on the stimulated secretion can be interpreted as resulting from the action of $H$ pylori at a step distal to the second messenger system - on the exocytotic mechanism of mucous cells (fig 5).

In the context of these results, it was important to determine whether the exocytotic machinery was the sole target of $H$ pylori, or whether this effect was accompanied by a reduction of glycoprotein synthesis. Together our findings point to a specific impairment of glycoprotein exocytosis in $H$ pylori infected mucous cells without any significant effect on mucus synthesis.

Interestingly, our results derived from an in vitro approach are in line with a recent preliminary report based on human antral biopsy specimens, suggesting that $H$ pylori alters the release of intracellular mucins into the lumen. ${ }^{18}$

The molecular mechanisms underlying the exocytotic defect are still unknown. The recent observation by Bell and Manning ${ }^{19}$ that Campylobacter jejuni causes a temporary brush border dysfunction in intestinal epithelial cells, has led to the suggestion that these organisms can selectively impair enzymes that are present at the apical surface. In the same way, $H$ pylori could affect exocytosis by impairing the fusion of mucus granule membranes to the apical surface. Alternatively, in view of recent findings suggesting that intimate attachment of $H$ pylori to cultured human gastric epithelial cells is associated with actin polymerisation, ${ }^{20}$ it may be hypothesised that these cytoskeletal changes can prevent secretory granules from reaching the exocytotic sites.

Finally, what is the pathological relevance of our findings? The fact that $H$ pylori selectively impairs the exocytotic response of mucous cells may have important pathological consequences. In fact, it is important to consider that the exocytotic response to a variety of physiological secretagogues such as inflammatory mediators constitutes the primary line of defence of the gastric mucosa faced with an emergency. In this context, we postulate that $H$ pylori may profoundly weaken this defence, thereby leading to cellular damage when the mucosa is exposed to various types of aggressive agents. We suggest that this indirect action may be more important than the direct cytotoxic action of the bacteria on the epithelial cells.

This work was supported in part by the Conseil Scientifique de la Faculté Bichet, by ARC, and by the Conseil Regional d'Aquitaine.

1 Graham DY. Campylobacter pylori and peptic ulcer disease. Gastroenterology 1989;96:615-25.

2 Bode G, Malfertheiner P, Ditschuneit H. Pathogenic implication of ultrastuctural findings in Campylobacter pylori related gastroduodenal disease. Scand $\mathcal{f}$ Gastroenterol 1988;23(suppl 142):25-39.

3 Chen XG, Correa P, Offerhaus J. Ultrastructure of the mucosa harboring Campylobacter-like organisms. $A m \mathcal{F}$ Clin Pathol 1986;86:575-82.

4 Thomsen LI, Gavin JB, Tasman-Jones C. Relation of Helicobacter pylori to the human gastric mucosa in chronic gastritis of the antrum. Gut 1990;31:1230-6

5 Tricottet V, Bruneval P, Vire O, Camilleri JP. Campylobacter-like organisms and surface epithelium abnormalities in active, chronic gastritis in humans: an ultrastructural study. Ultrastruct Pathol 1986;10:113-22.

6 Augeron C, Laboisse CL. Emergence of permanently differentiated cell clones in a human colonic cancer cell line in culture after treatment with sodium butyrate. Cancer Res 1984;44:3961-9.

7 Roumagnac I, Laboisse CL. A mucus-secreting human colonic epithelial cell line responsive to cholinergic stimulation. Biol Cell 1987;61:65-8.

8 Roumagnac I, Laboisse CL. A simple immunofiltration assay for mucins secreted by a human colonic epithelial assay for mucins secreted by a human colonic
cell line. $\mathcal{F}$ Immunol Methods 1989;122:265-71.

9 Laburthe M, Augeron C, Rouyerfessard C, Roumagnac I, Maoret JJ, Grasset E, Laboisse C. Functional VIP receptors in the human mucus-secreting colonic epithelial cell line $\mathrm{Cl}$. 16E. Am Y Physiol 1989;256:G443-50.

10 Mégraud F, Bonnet F, Garnier M, Lamouliatte H. Characterization of "Campylobacter pyloridis" by culture, enzymatic profile and protein content. $f$ Clin Microbiol 1985;22:1007-10.

11 Fogh J, Trempe G. New human tumor cell lines. In: Fogh J, ed. Human tumor cells "in vitro". New York: Plenum Press, 1975:115-41.

12 ChenTR. "In situ" detection of mycoplasma contamination in cell cultures by fluorescent Hoechst 33258 stain. Exp in cell cultures by fluorescen

13 Néman-Simha V, Mégraud F. In vitro model for Campylobacter pylori adherence properties. Infect Immun 1988;56:3329-33.

14 LaMont JT, Ventola A. Stimulation of colonic glycoprotein synthesis by dibutyryl cyclic AMP and theophylline. Gastroenterology 1977;72:82-6.

15 Maoret J, Font J, Augeron C, et al. A mucus-secreting human colonic cancer cell line-Purification and partial characterization of the secreted mucins. Biochem $f$ 1989;258:793-9.

16 Bara J, Loisillier F, Burtin P. Antigens of gastric and intestinal mucous cells in human colonic tumours. $\mathrm{Br} F$ Cancer 1980;41:209-21.

17 Seidler U, Sewing KF. Ca-2 + -dependent and Ca-2 + -independent secretagogue action on gastric mucus secretion in rabbit mucosal explants. Am $\mathcal{F}$ Physiol 1989;256: G739-46.

18 Stamm CP, Larsen B, Maydonovitch CL, Wong RKH, Yang $\mathrm{K}$, Shea-Donohue T. Alterations in carbohydrates present in secreted and intracellular gastric mucus in Helicobacter pylori gastritis. Gastroenterology 1991;100: A167.

19 Bell JA, Manning DD. Role of temporary intestinal brush border dysfunction in Campylobacter jejuni diarrhea. Curr Microbiol 1990;21:355-9.

20 Smoot DT, Gillam T, Phelps P, Résau JH, Foxall PA, Mobley HLT. Intimate attachment of Helicobacter pylori to cultured human gastric epithelial cells is associated to cultured human gastric epithelial cells is associated
with actin polymerization. Microbiol Ecol Health Dis 1991; with actin 